УДК 373+612.776.1

\title{
ВЛИЯНИЕ СИСТЕМАТИЧЕСКИХ ЗАНЯТИЙ ФИЗИЧЕСКИМИ УПРАЖНЕНИЯМИ РАЗНОЙ ИНТЕНСИВНОСТИ И ПРОДОЛЖИТЕЛЬНОСТИ НА ФУНКЦИОНАЛЬНОЕ СОСТОЯНИЕ ДЕТЕЙ 5-6 ЛЕТ ПРИ ИНФОРМАЦИОННЫХ НАГРУЗКАХ
}

\author{
Чернова Мария Борисовна \\ кандидат педагогических наук, доцент \\ Криволапчук Игорь Альлерович \\ доктор биологических наук, профессор \\ Васильева Римма Михайловна \\ кандидат биологических наук, старший научный сотрудник \\ Федеральное государственное бюджетное научное учреждение \\ «Институт возрастной физиологии» \\ Российской академии образования \\ Савушкина Елена Васильевна \\ старший преподаватель \\ Учреждение образования «Гродненский государственный \\ университет имени Янки Купалы»
}

\begin{abstract}
Аннотация. На основе двухфакторного дисперсионного анализа установлено, что долговременные адаптационные изменения ФС организма детей 5-6 лет во многом обусловлены интенсивностью и объемом физической нагрузки, а также их взаимодействием. Влияние этих факторов на ФС носит однонаправленный характер: c увеличением объема и интенсивности благоприятные функциональные изменения нарастают. С интенсивностью и объемом физической нагрузки в возрасте 5-6 лет связаны вегетативное обеспечение и психофизиологическая цена информационной нагрузки, эмоциональное состояние, физическая работоспособность и двигательная подготовленность.

Ключевые слова: систематические занятия, недельный объем и интенсивность физической нагрузки, функциональное состояние, информационная нагрузка, дисперсионный анализ.
\end{abstract}




\title{
THE INFLUENCE OF SYSTEMATIC PHYSICAL EXERCISES OF VARYING INTENSITY AND DURATION ON THE FUNCTIONAL STATE OF 5-6 YEAR OLD CHILDREN WITH INFORMATIONAL LOADS
}

Chernova Maria Borisovna

$\mathrm{PhD}$ (Cand. Ped. Sci.), assistant professor

Krivolapchuk Igor Allerovich

PhD (Doc. Biol. Sci.), professor

Vasilieva Rimma Mikhailovna

$\mathrm{PhD}$ (Cand. Biol. Sci.), senior research officer The Federal State Budget Scientific Institution «Institute of Developmental Physiology of the

Russian Academy of Education»,

Savushkina Elena Vasilievna senior lecturer

Yanka Kupala State University of Grodno

\begin{abstract}
Two-factor analysis of variance showed that long-term adaptive changes in the FS of 5-6-year-old children are largely due to the intensity and volume of physical activity, as well as their interaction. The influence of these factors on FS is unidirectional: increased volume and intensity leads to increased beneficial functional changes. The intensity and volume of physical activity at the age of 5-6 years are associated with autonomic support and psychophysiological cost of information load, emotional state, physical performance and motor fitness.
\end{abstract}

Key words: systematic exercise, weekly volume and intensity of physical activity, functional state, information load, analysis of variance.

Современные научные данные показывают, что между параметрами физической нагрузки и функциональным состоянием (ФС) организма детей существует зависимость типа «доза-эффект» $[8,6,7,9]$. Вместе с тем отсутствует необходимый объем научных данных о зависимости «дозаэффект» между физической активностью и показателями ФС детей дошкольного возраста при информационных нагрузках. Комплексные исследования влияния систематических занятий физическими упражнениями, регламентированных по интенсивности и объему воздействия на различные 


\section{МОДЕРНИЗАЦИЯ СОВРЕМЕННОГО ОБРАЗОВАНИЯ: АНАЛИЗ ОПЫТА И ТЕНДЕНЦИЙ}

аспекты функционального состояния дошкольников в информационных нагрузок не проводились. Применительно к контингенту детей дошкольного возраста данная проблема остается совершенно неизученной.

Цель исследования - выявить влияние факторов «интенсивность» и «объем» физической нагрузки в условиях систематических занятий физическими упражнениями на функциональное состояние детей 5-6 лет.

\section{Методика}

В исследовании приняли участие практически здоровые дети 5-6 лет $(\mathrm{n}=85)$. Организация исследования соответствовала принципам биомедицинской этики.

Для проведения педагогического эксперимента сформированы 4 экспериментальные группы. Группа I выполняла комплексы упражнений длительностью 60 минут в неделю с интенсивностью 40-50 \% максимального пульсового резерва (МПР), группа II - 60 минут в неделю с интенсивностью 70-80 \% МПР, группа III - 120 минут в неделю с интенсивностью 40-50 \% МПР, группа IV - 120 минут в неделю с интенсивностью 70-80 \% МПР. Продолжительность исследования превысила 30 недель.

Информационная нагрузка задавалась с помощью фигурных таблиц. Тестирование проходило в покое и при выполнении тестовых информационных нагрузок с комфортной (автотемп) и высокой скоростью (максимальный темп). По результатам выполнения каждого задания рассчитывали объём работы (А) и коэффициент продуктивности (Q). Скорость и продуктивность работы оценивались также в условиях детского дошкольного учреждения до $\left(\mathrm{A}_{\text {до }}, \mathrm{Q}_{\text {до }}\right)$ и после $\left(\mathrm{A}_{\text {после }}, \mathrm{Q}_{\text {после }}\right)$ занятий [3]. Индексы показателей $0,1,2-$ характеризуют ФС в покое, при информационной нагрузке в авто- и максимальном темпе, соответственно.

Анализ вариабельности сердечного ритма в состоянии покоя и при тестовых когнитивных нагрузках использовали для оценки степени напряженности регуляторных систем [Баевский]. Измерение ЭКГ-сигнала для анализа вариабельности сердечного ритма производили в положении сидя во II стандартном отведении. Рассчитывали частоту сердечных сокращений (ЧСС), среднюю продолжительность кардиоинтервалов (RRNN), моду (Mo), амплитуду моды (AMo), разброс кардиоинтервалов (MxDMn), среднеквадратическое отклонение (SDNN), стресс-индекс (SI). 
Систолическое (СД) и диастолическое (ДД) давление крови регистрировали с помощью механического тонометра в соответствии с рекомендациями ВОЗ. Рассчитывали среднее (САД) и пульсовое (ПД) давление, двойное произведение (ДП), показатель эффективности кровообращения (СД/ЧСС), вегетативный индекс Кердо (ВИК). Эффективность-психофизиологическую цену деятельности определяли посредством расчета соотношений: А/ЧCC, A/SI, A/ДП, Q/ЧCC, Q/SI, Q/ДП, [3].

Для оценки физической работоспособности определяли мощность нагрузки при пульсе 170 уд/мин (PWC170), интенсивность накопления пульсового долга (ИНПД), максимальное потребление кислорода (МПК), ватт-пульс (ВтП), максимальную силу (МС) и время удержания $\left(\mathrm{t}_{2 \mathrm{BT} / \kappa \mathrm{\kappa}}, \mathrm{t}_{4 \mathrm{~B} \mathrm{~T} / \mathrm{\kappa r}}\right)$ «до отказа» нагрузок 2 и 4 Вт/кг [3]. Находили мощность нагрузок, время выполнения которых составляло 1 (W1), 40 (W40), 240 (W240), 900 с (W900), коэффициенты, характеризующие аэробную емкость (b) и соотношение возможностей аэробного и анаэробно-гликолитического механизмов (а) [2].

Батарея моторных тестов включала: наклон вперёд; прыжок в длину с места; бег 20 метров с хода; челночный бег 4x9 м; шестиминутный бег; поднимание туловища из положения «лёжа на спине» за 1 минуту.

Для диагностики эмоционального статуса и личностных особенностей детей использовали проективную методику Р. Тэммл «Выбери нужное лицо» (рассчитывали индекс тревожности - ИТ), восьмицветовой тест М. Люшера (диагностировали ситуативную тревожность - СТ и коэффициент вегетативного тонуса - КВТ) [5]. Для статистической обработки полученного материала использовали пакет прикладных программ Statistica.

\section{Результаты исследования}

Для оценки долговременных эффектов влияния факторов «интенсивность» и «недельный объем нагрузки» проводили дисперсионный анализ. Использовали результаты педагогического эксперимента. Анализ двухфакторных комплексов наряду с избирательным воздействием каждого фактора в отдельности учитывает и их совместное действие на результативный признак.

Интенсивность и недельный объем нагрузки рассматривались в качестве независимых факторов. Использовались две градации интенсивности (40-50 и 
70-80 \% МПР) и две градации недельного объема нагрузки (60 и 120 минут). Оценку влияния факторов на результативный признак $(\mathrm{hx} 2)$ проводили на основе метода Плохинского [4].

При обследовании детей 5-6 лет получены результаты, свидетельствующие о том, что оцениваемые компоненты нагрузки значимо ( $<0,05-0,01)$ воздействуют на ФС. Долговременные эффекты факторов А (интенсивность) и В (недельный объем) как в отдельности, так и в их взаимодействии статистически значимы (рис.).

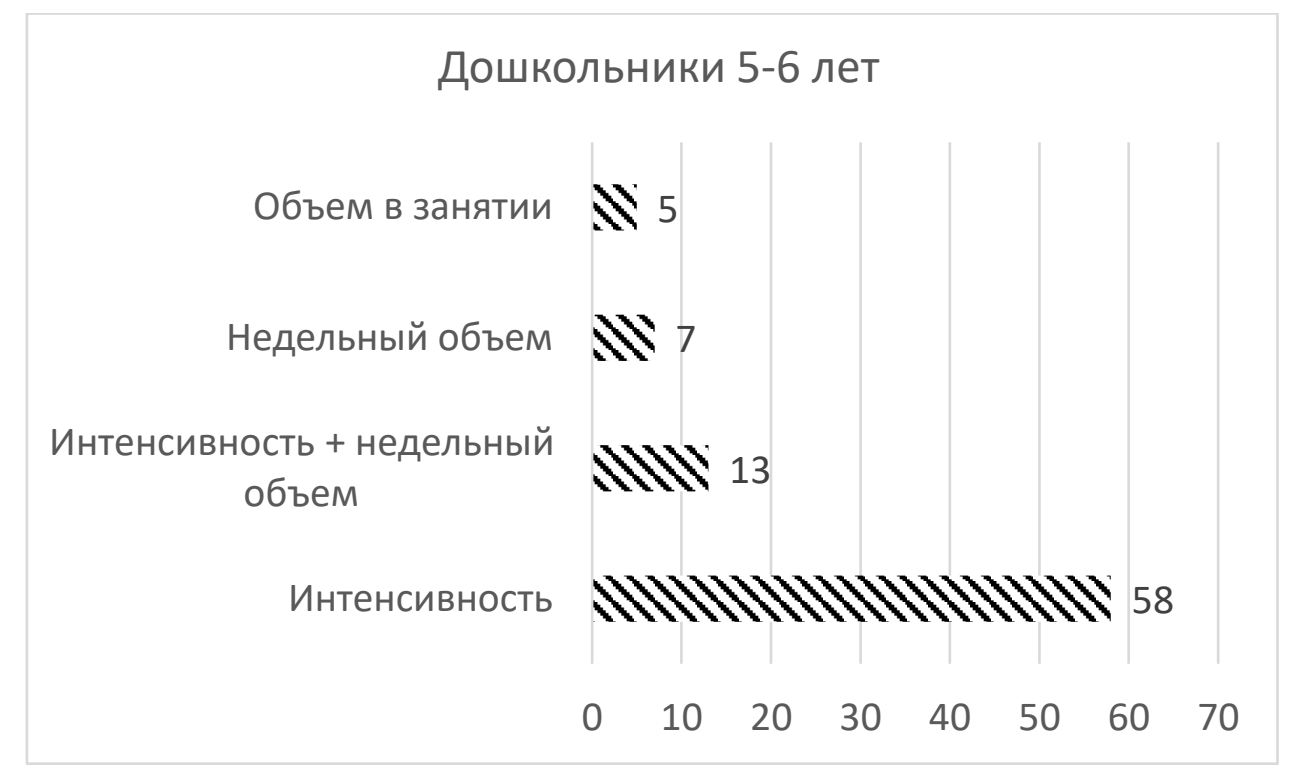

\section{Рис.1. Влияние факторов «интенсивность» и «объем» нагрузки на показатели ФС детей}

Примечание. Горизонтальная ось - количество показателей.

Средняя интенсивность влияет на $58\left(\mathrm{MxDMn}_{0}, \mathrm{ЧCC}_{0}, \mathrm{CД}_{0}, Д_{0}, \mathrm{CAД}\right.$, ДП $, \mathrm{MxDMn}_{1}, \mathrm{ЧCC}_{1}, \mathrm{SI}_{1}, \mathrm{CД}_{1}$, ДП 1 , ДД 1, ВИК $, \mathrm{CAД}_{1}, \mathrm{CД} / \mathrm{ЧCC}_{1}, \mathrm{MxDMn}_{2}$, $\mathrm{YCC}_{2}, \mathrm{RRNN}_{2}, \mathrm{Mo}_{2}, \mathrm{SI}_{2}, \mathrm{CД}_{2}, Д_{2}$, ДД 2, ВИК $2, \mathrm{CAД}_{2}, \mathrm{CД} / \mathrm{ЧCC}_{2}$, количество заболеваний, $\mathrm{A}_{1}, \mathrm{Q}_{1}, \mathrm{~A}_{2}, \mathrm{Q}_{2}, \mathrm{~A} / \mathrm{ЧCC}_{1}, \mathrm{~A} / \mathrm{SI}_{1}, \mathrm{~A} / Д \Pi_{1}, \mathrm{Q} / \mathrm{ЧCC}_{1}, \mathrm{Q} / \mathrm{SI}_{1}, \mathrm{Q} / Д \Pi_{1}$, $\mathrm{A} / \mathrm{ЧCC}_{2}, \mathrm{~A} / \mathrm{SI}_{2}, \mathrm{~A} / Д \Pi_{2}, \mathrm{Q} / \mathrm{ЧCC}_{2}, \mathrm{Q} / \mathrm{SI}_{2}, \mathrm{Q} / Д \Pi_{2}$, ИТ $_{2}, \mathrm{PWC}_{170}$, МПК, ИНПД $2 \mathrm{Bт} /$ кг, $\mathrm{t}_{1}, \mathrm{t}_{2}, \mathrm{~b}, \mathrm{~W}_{40}, \mathrm{~W}_{240}, \mathrm{~W}_{900}$, наклон, прыжок, бег в течение 6 мин, бег 20 м, поднимание туловища, общий балл физической подготовленности).

С недельным объемом нагрузки связаны изменения 7 (ПД $2, \mathrm{~A} / \mathrm{SI}_{1}, \mathrm{~A} / \mathrm{SI}_{2}$, $\mathrm{KBT}_{1}$, МПК, абсолютные и относительные значения $\mathrm{PWC}_{170}$ ) показателей ФС.

Взаимодействие факторов $\mathrm{AB}$ оказалось существенным в отношении 13 
$\left(\mathrm{CД}_{1}, Д_{1}\right.$, ВИК $_{1}$, САД 1, СД/ЧСС $1, \mathrm{CД}_{2}, \Pi_{2}, \mathrm{CД} / \mathrm{ЧCC}_{2}, \mathrm{Q}_{1}, \mathrm{Q} / \mathrm{ЧCC}_{1}, \mathrm{Q} / Д_{1}$, $\left.\mathrm{A} / Д \Pi_{2}, \mathrm{Q} / Д \Pi_{2}\right)$ переменных.

Показатель силы влияния факторов (hx2) находился в диапазоне от 4 до $44 \%$, что отражает зависимость общего варьирования изучаемых переменных от интенсивности и недельного объема физической нагрузки.

\section{Заключение}

На основе двухфакторного дисперсионного анализа установлено, что долговременные адаптационные изменения ФС организма детей 5-6 лет во многом обусловлены интенсивностью и объемом физической нагрузки, а также их взаимодействием. Влияние этих факторов на ФС носит однонаправленный характер: с увеличением объема и интенсивности благоприятные функциональные изменения нарастают. С интенсивностью и объемом физической нагрузки в возрасте 5-6 лет в условиях систематических занятий физическими упражнениями связаны вегетативное обеспечение и психофизиологическая цена информационной нагрузки, эмоциональное состояние, физическая работоспособность и двигательная подготовленность.

Полученные результаты свидетельствуют, что средняя интенсивность нагрузки в занятии оказывает более существенное влияние на ФС детей 5-6 лет, чем ее объем. Исследование выполнено при финансовой поддержке Российского фонда фундаментальных исследований (проект № 19-013-00127).

\section{Список литературы}

1. Баевский, Р.М. Основные принципы измерения уровня здоровья // Проблемы адаптации и учение о здоровье / Р.М. Баевский. - М.: Изд-во РУДН, 2006. - С. 119-165.

2. Баранцев, С.А. Формирование кинематической структуры ациклических локомоций и биоэнергетики мышечной системы мальчиков школьного возраста / Баранцев С.А., Зайцева В.В., Пискова Д.М. // Новые исследования, 2009. - №3 (20). - С. 62-72.

3. Криволапчук, И.А. Особенности факторной структуры функционального состояния организма мальчиков и девочек 6-7 лет / И.А. Криволапчук, М.Б. Чернова // Физиология человека. - 2021. - Т. 47. №2. - C. 32-44. 
4. Лакин, Г.Ф. Биометрия: учеб. пособие для биолог. спец. вузов / Г.Ф. Лакин. - М.: Высшая школа, 1990. - 352 с.

5. Собчик, Л.Н. Метод цветовых выборов - модификация цветового теста Люшера / Л.Н. Собчик. - СПб.: Речь, 2006. - 128 с.

6. Global Recommendations on Physical activity for Health. - Geneva, World Health Organization, 2010. - 60 p.

7. Janssen, I. Systematic Review of the Health Benefits of Physical Activity in School-Aged Children and Youth/ I. Janssen, A. Leblanc//International Journal of Behavioural Nutrition and Physical Activity, 2010. Vol. 7, №40. - p. 1-16.

8. Physical Activity and Public Health. A Recommendation From the Centers for Disease Control and Prevention and the American College of Sports Medicine // JAMA. - 1995. - Vol. 273, № 5. - P. 402-407.

9. The Physical Activity Guidelines for Americans / K.L. Piercy, R.P. Troiano, R.M. Ballard, S.A. Carlson, J.E. Fulton, D.A. Galuska, S.M. George, R.D. Olson // JAMA. - 2018. - Vol. 320(19). - P. 2020-2028.

(С М.Б. Чернова, И.А. Криволапчук, Р.М. Васильева, Е.В. Савушкина, 2021 